\title{
Literatura indígena amazónica Shipibo-conibo y el kené de la palabra de Lastenia Canayo
}

\author{
Amazonian indigenous literature Shipibo-coniboand \\ the kené of the word of Lastenia Canayo
}

\author{
GONZALO ESPINO RELUCÉ \\ Universidad Nacional Mayor de San Marcos, EILA-UNMSM \\ gespino@unmsm.edu.pe
}

Esta comunicación propone el rapto de la escritura como expresión de la cultura indígena que se traslada a un nuevo soporte. El fenómeno se explica como un hecho de reciente data, los indígenas asumen la escritura como una tecnología que instrumenta la comunicación de su propia cultura e instala una nueva problemática: el tránsito del sujeto de la cultura que comunica su cosmovisión en nuevos escenarios, cuando menos dos situaciones, el reacomodo de las formas tradicionales en espacios relativamente nuevos, y el hecho de que como recopilador se convierte en escritor. Por lo que esta comunicación caracteriza a esta escritura como el kené de la palabra, desde la cultura y la trasmisión de la cultura, nos referimos a la cultura Shipibo-conibo, en la palabra y diseño de Lastenia Canayo, Los dueños del mundo Shipibo (2004). ${ }^{1}$

Palabras claves: Amazonía, Shipibo-conibo, kené, narrativa, Lastenia Canayo, siglo XXI.

This paper proposes the Rapture of writing as an expression of the indigenous culture that moves to a new support. The phenomenon is explained as a made from recent data, the indigenous assume it writing as a technology that implements the communication of its own culture and installs a new problematic: the transit of the subject of the culture that communicates their worldview in new scenarios, when less two situations, the rearrangement of the traditional forms in relatively new spaces, and the fact that as a collector becomes writer. So this paper characterizes this writing as the Kene of the word, since the culture and transmission of culture, we refer to Shipibo-conibo culture, in Word and design by Lastenia Canayo, Los dueños del mundo Shipibo (2004).

Key words: Amazon, Shipibo-conibo, kené, narrative, Lastenia Canayo, twenty-first century.

\footnotetext{
${ }^{1}$ El presente trabajo forma parte de las investigaciones Proy. UNMSM 140303011 y 1603030 71, y se adscribe, a su vez, al proyecto Fondecyt $N^{\circ} 1141007$.
} 
La escritura indígena amazónica tiene reciente data. Desde mediados del siglo XX, las investigaciones antropológicas abundan y en el balance de fin de siglo podemos advertir una importancia creciente de escritores ribereños de la selva del Perú. Sin embargo, la producción discursiva indígena sigue sus cauces tradicionales, lo oral; es decir, se corresponde con los rituales y su saga que suele decirse en la maloca, en el mitayo o la caza, en el trabajo cotidiano; y reitera el mito, la historia y la vida cotidiana de los pueblos, las mismas que pueden estar refrendadas en diseńos, dibujos, pinturas faciales, trazos en ceramios o tejidos, con diversos registros. En las últimas tres décadas han aparecido nuevos tipos de escritura, que parten de la recopilación y que, llevada al rapto de la letra por indígenas, da lugar a un tipo de escritura que llama la atención por la forma cómo esta se instala en el mundo indígena y en el otro letrado. Al mismo tiempo, varias de estas escrituras cuestionan su propia realización al estar acompañadas por dibujos y pinturas que alcanza diversos valores, que aquí preferimos asociarla al kené de la palabra.

\section{ESCENARIOS LETRADO Y SOCIAL}

La publicación de varios textos de narrativas de los pueblos indígenas amazónicos pone en primer plano un problema: los tránsitos de la voz a la escritura, es decir, cómo culturalmente una tecnología que no ha sido de su dominio altera, disgrega o afirma las formaciones discursivas tradicionales. Por lo que me interesa rastrear en estas publicaciones el continente de una tecnología que encierra la palabra voz a la que describo como la condición primaria de la comunicación, lenguaje con que se expresan en diversas situaciones en tanto memoria, ancestros y presencia contemporánea. En ese sentido me interrogo, ¿hasta qué punto la voz se percibe como oralitura tal como lo entiende Elicura Chihuailaf? Todo parece indicar que en la memoria de la voz podemos percibir un relato que viene de una colectividad en el ahora, la cultura de una etnia; es decir, como la palabra que se inscribe desde la palabra que se habla y se compromete con los ancestros, esto es: "nuestra Palabra, ya inscribiéndose, pero al lado de la oralidad -"oralitura", decimos los oralitores-. La palabra sostenida en la Memoria, movida por ella, desde el hablar de la fuente que fluye en las comunidades" (Chihuailaf, 1999: 62). Mejor aún "La palabra escrita no como un mero artificio lingüístico (no me estoy refiriendo a la función de artificio que todo lenguaje contiene permanentemente) sino como un compromiso en el presente el Sueño y la Memoria” (Chihuailaf, 1999: 62).

En segundo lugar: se trata de textos que suponen un doble estatuto comunicacional, textos biculturales, se escribe para los propios “lectores" indígenas (en la lengua originaria) y se hace también para "aquellos" que no hablan ni conocen la lengua ni la cultura (en la lengua de transacciones, el español). De manera que me interesa ver cómo la escritura, en tanto tecnología novedosa, resulta un instrumento que surte efecto para la cultura en tanto registro de otra naturaleza. Esto en relación a otros tipos de soportes, pienso en formatos tradicionales (diseños, marcas, repeticiones, etc.), o tecnologías actuales (grabación, video, 
celular, ciberespacio) y a los consensos alcanzados para la escritura de los textos asháninkas, shipibos, harakbut, ese eja y yanesha (Minedu, 2013).

Sin embargo, la pregunta vuelve otra vez sobre el castellano y cómo la letra del otro la representa y alerta sobre los temas y asuntos que se registran como parte de lo que comúnmente identificamos como literatura oral (mitos, tradiciones, historias, leyendas, cotidianidades, saberes, etc.) y los repertorios, que de un lado evidencian que el tiempo de narración corresponde al ahora contemporáneo, su referente temporal, respecto a la trasmisión de la memoria y tradición oral. Nuevamente, podemos preguntar, ¿̧hasta qué punto estas estructuras narrativas abandonan su condición de relatos tradicionales para situarse como narrativas o historias indígenas? En todos los casos, hay que sugerir, que se trata de escrituras que vienen con el aura de un sujeto que definimos como indígena en el sentido de instalarse desde -o reclamar- una pertenencia (Halls, 2010).

Hasta aquí la reseña disciplinar, por lo que haré una breve incursión sobre la situación indígena en el Perú. La población indígena en el caso peruano pasó de los dos tercios a inicio del siglo XX a una manifestación incierta, representada por cerca del 17\%, es decir, inversión de la tasa social. El dato no tendría por qué ser problema, pero dicha información esconde el despojo, la servidumbre y la pobreza a la que fueron sometidas las poblaciones que despectivamente se les denominó la "mancha india" en los Andes y la invisibilización de las poblaciones indígenas amazónicas en función de la riqueza del bosque tropical. La creación de la nación peruana se inspiró entre los criollos y los andinos, el modelo fue criollo, y a fines del siglo XIX empieza el indio a convertirse en tema académico y se lo vincula con la nación. Durante la primera mitad del siglo XX se discute el tema de la nación peruana, lo andino pasaría a ser el componente fundacional e identitario, su referente serían los andinos del sur del Perú. De esta suerte, la Amazonía apareció como espacio a conquistar y colonizar. La Amazonía no aparece en el imaginario peruano sino tardíamente

Tratándose de pueblo y cultura, conviene precisar que durante el siglo XX se ha producido una transformación del bosque en ciudades en la que ribereńos y colonos han depredado el bosque. Si primero fue el caucho, luego el petróleo, ahora continúa la tala de madera y por supuesto, el asunto del oro y el narcotráfico que destruyen espacios vitales de la selva. La historia fue en todos los casos dramática, con visos de tragedia. Me refiero a lo ocurrido con los indígenas en el periodo del caucho que utilizaron a los indígenas para capturar otros indígenas, no solo para el desalojo y desplazamiento de sus territorios, sino explotarlos, esclavizarlos y matarlos (Chirif-Cornejo, 2009). La cesión de territorios para la exploración petrolera, la tala indiscriminada del bosque y conversión de los espacios de vida arrinconó y aceleró los procesos de contacto y despojo de los territorios indígenas. Si bien existen, y podemos coincidir en ello, que la Amazonía empieza a ser estudiada sistemáticamente en la década de los 70 (CILA 2010; Mayor-Bobmer 2009; San Román 1994; Varese 1973). Es durante el conflicto armado interno (1980-2000), que se vivió como tragedia, toda vez que las poblaciones nativas fueron esclavizadas por Sendero Luminoso (PCP-SL), en particular los pueblos 
indígenas Asháninkas $(\mathrm{CVR}, 2003)^{2}$. Del mismo modo, no está de más recordar que también la Amazonía es la zona de mayor incidencia del narcotráfico.

Es recién en este siglo que las poblaciones indígenas amazónicas alcanzan notoriedad cuando Alan García, entonces presidente de la República (2006-2011), consideró que estos "no son ciudadanos de primera clase" a propósito de lo que se conoce como el baguazo, el 5 junio de $2009^{3}$, cuyo saldo de intervención policial desató el enfrentamiento con la población indígena que defendía su territorio y a la consulta previa. Como consecuencia del conflicto resultaron 34 muertos (oficialmente un desparecido) ${ }^{4}$.

Actualmente se considera, oficialmente, que existen 43 pueblos amazónicos distribuidos en territorios de nuestra Amazonía (Minedu, 2013), con 43 lenguas que pertenecen a 17 familias lingüísticas, estos pueblos, en cada uno de sus territorios desarrollan su vida, entre el bosque y el río, la continuidad de formas exitosas de existencia y la defensa de la floresta amazónica, entre una larga historia y su reciente incorporación al imaginario nacional, pero los cambios operados por la modernización han limitado las tradicionales vías de tránsito y modificado el dominio de los territorios. Estos pueblos oscilan entre la continuidad y la extinción de la comunidad nativa, por lo que la comunidad tradicional ha empezado a vivir cambios insospechables. Las dos poblaciones indígenas amazónicas con la más alta densidad poblacional son los Asháninca 67,724 y los Shipibo-Conibos 22.629 habitantes (Censo Nacional 2007); se han identificado cuatro lenguas en situación límite, "lenguas en peligro", estas son Bora, Murui-muinani, Yagua y Yanesha.

\section{NARRATIVAS INDÍGENAS}

Con propiedad se puede hablar de escritores indígenas como un hecho reciente. La producción escrita es significativa, aunque no abundante. En el caso peruano, pasa por algunas problemáticas sobre la condición de autor y su autodefinición, asunto que no ocurre con las poblaciones indígenas andinas, que no se reconocen como indígenas, sino que se

\footnotetext{
${ }^{2}$ La Comisión de la Verdad y Reconciliación (CVR) en el Informe Final señala: "No existen datos precisos, pero la mayoría de especialistas e instituciones calculan que de 55 mil Asháninkas, cerca de 10 mil Asháninkas fueron desplazados forzosamente en los valles del Ene, Tambo y Perené, 6 mil personas fallecieron y cerca de 5 mil personas estuvieron cautivas por PCP-SL Luminoso, y se calcula que durante los ańos del conflicto desaparecieron entre 30 y 40 comunidades Asháninka” (CVR 2003: 241)

${ }^{3}$ Ver los documentales La Espera (Historias del Baguazo), dirigido por Fernando Vílchez Rodríguez <https:// www.youtube.com/watch?v=pVkONDVbe-w> y El choque de dos mundos" "When Two Worlds Collide"), codirigido por Heidi Brandenbur y Matew Orzel.

${ }^{4}$ Es sintomático que esto se replique el 2016 con el caso de la comunidad indígena urbana Shipibo-Konibo de Cantagallo, en la que el alcalde de Lima Luis Castańeda muestra su desprecio por la cultura y la población vulnerable, al no haber resuelto el problema del espacio para vivienda luego del incendio que se produjera a fines de noviembre de ese año. Cf. La cronología de la Defensoría del Pueblo al respecto: http://www.defensoria.gob. pe/blog/cronologia-caso-comunidad-indigena-urbana-shipibo-konibo-de-cantagallo/
} 
autodefinen como quechuas (o runa) o aymaras (o hakhe), según sea el caso o en general, el elíptico campesino. Es en estas poblaciones, en especial, la quechua que tiene una larga tradición de escritura, desde 1560 con la Plática de fray Domingo de Santo Tomás; aunque en términos contemporáneos, postulamos que se inicia con Canas $i$ sus relámpagos (1947) y la publicación de Taki parwa de Kilko Warak’a (1955). Con relación a las poblaciones amazónicas, resulta más compleja, pues se trata de prácticas tardías, que en este siglo XXI vienen acompañadas por la aparición de un apreciable núcleo de intelectuales indígenas, como ha ocurrido con los quechuas, y los consensos logrados en torno a los alfabetos de las lenguas originarias (Minedu 2013: 90-95).

Desde fines del siglo pasado se han intentado proyectos autónomos, como el que realizó AIDESEP con el título de Cácámeewa y otros relatos indígenas y ribereños (1992), si bien los relatos proceden de los pueblos indígenas amazónicos, estos se publican en español. No ocurre lo mismo con la publicación de la Fundación Cultural Shipibo-Conibo, pues Non requenbaon shinan, El origen de la cultura Shipibo-Conibo (1998) llega en la lengua indígena y la dominante. Más adelante, con la publicación de AMABICEB, Opempe. Oshintsinka noñane. El poder de mi lengua. Relatos orales asháninkas y nomatsiguengas (2009), en edición bilingüe. Los escenarios de escritura se concentran en un nuevo grupo de textos, me refiero a Lastenia Canayo, Los dueños del mundo Shipibo (2004); Domingo Casancho Leguía, Irogotane nomatsigenga (2010), Dina Ananco, wanpis, que trabaja la memoria de la historia y ha narrado los violentos sucesos del 5 de junio del 2009 en su cuento "Baguazo" (2013). Rember Yahuarcani, huitoto, ha publicado textos para niños, en castellano, El Sueño del Buinaima (2010) y Fidona y el bosque de estrellas (2015). Más recientemente, el 2015, un par de libros que llama la atención por lo que configura este tránsito del recopilador al narrador: Relatos orales ashaninkas de Leo Laman Almonacid Leya y Relatos orales harakbut de Yesica Patiachi Tayori escrita por pobladores de dichos pueblos. Ambos libros tienen su origen en investigaciones de tesis de pedagogía vinculadas a la Educación Intercultural Bilingüe 5 . Los Relatos orales ashaninkas de Leo Laman Almonacid Leya proviene de la tesis Elaboración de un texto de lecto-escritura en la lengua ashaninka para los alumnos del III ciclo de educación primaria, realizada en la comunidad de Quempiri, en el río Tambo, SatipoJunín (Almonacid 2015: 5) y Relatos orales harakbut tiene su génesis en la tesis de pedagogía Literatura oral harakbut (2007), presentada en Puerto Maldonado, por Yesica Patiachi Tayori (2015: 4). Ya no son el antropólogo ni el cura ni el ILV, me refiero al Instituto Lingüístico de Verano como en Cuentos folklóricos de los ashaninkas (2 t., 1985-6); ni el maestro Heinrich Helberg Chávez: Mbaisik en la penumbra del atardecer: literatura oral del pueblo Harakmbut (1996), sino los habitantes de dichos pueblos. Asimismo, el Ministerio de Cultura publica de María C. Chavarría Eseha echiikiana esoiho (2015) que trabajara con los abuelos Ese eja ${ }^{6}$.

\footnotetext{
${ }^{5}$ Provienen de instituciones de formación docentes; Almonacid Leya estudió en el Programa de Formación de Maestros Bilingües de la Amazonía Peruana (FORMABIAP) de Iquitos y Patiachi Tayori lo hizo en el Instituto Superior Pedagógico Público "Nuestra Señora de Rosario" del Puerto Maldonado, Madre de Dios.

${ }^{6}$ También circulan El libro sagrado de los Cashinahuas (2013) y Mitos y leyendas de la nación Yanesha (2012) que
} 
Sin embargo, lo que llama la atención, de manera especial, es que sean escritos por integrantes de las respectivas etnias, que al igual que los quechuas, han llegado a aquello que José Carlos Mariátegui (1928) anunciara, una literatura indígena vendría cuando los propios indios la escriban:

La literatura indigenista no puede darnos una versión rigurosamente verista del indio. Tiene que idealizarlo y estilizarlo. Tampoco puede darnos su propia ánima. Es todavía una literatura de mestizos. Por eso se llama indigenista y no indígena. Una literatura indígena, si debe venir, vendrá a su tiempo. Cuando los propios indios estén en grado de producirla. (Mariátegui [1928] 1987: 335. Énfasis mío).

No se trataría en consecuencia de una escritura solidaria (el mestizo, el antropólogo, el cura) ni del sujeto que colapsa con su referente, sí de un sujeto de escritura que pertenece al referente y está en capacidad para escribir desde su propia cultura. Es esto lo que llama la atención. En líneas generales estos textos recogen lo central de sus propias culturas. Es decir, sus mitos fundacionales y los ciclos que se corresponde con la vida de la gente. El tiempo de la escritura no se ubica en la distancia de la voz, que el escrito suspende, por lo que el tiempo es el ahora y no hay la condición de un sujeto que a su vez se siente parte. Aun cuando pudiera encontrarse cierta intromisión del especialista en el texto, su novedad no radica en el exotismo, sino en la condición de sujeto de enunciación y de enunciado que traza una escritura reciente, es decir, una escritura fresca, casi inaugural, que nos lleva por los avatares distantes de los ancestros y de los mitos contemporáneos. Este escenario nos permite postular dos cuestiones: la primera está vinculada con el papel que cumple el sujeto de enunciación, que ha dejado de ser el informante, por lo que se convierte en el propio trascriptor de su cultura. El acto de fijar representa a su vez a una manera de preservar la propia cultura y al mismo tiempo recrearla. La segunda pone en cuestión, en este tránsito, las formas tradicionales de trasmisión del relato, por lo que habría que admitir una nueva configuración desde el lado indígena, que para el caso Shipibo-conibo denomino como el kené de la palabra.

La noción de recopilar resulta insuficiente para describir un nuevo ciclo de narradores. Si es cierto que se trabaja con la palabra de la comunidad, que se desliza en primer lugar, un acercamiento al mundo de la cultura ancestral, cotidiano, histórico, que esta se puede traducir en tradiciones orales (mitos, leyendas, historias, decires, fórmulas especiales, etc.) y que son llevadas a la escritura, en el caso de los recopiladores indígenas de este siglo, aparece un nuevo fenómeno: el narrador indígena. Por lo que planteo, para el caso de los recopiladores y recopiladoras indígenas un nuevo estatus, semejante a lo que ocurrió con el testimonio en la década de 1970. La relación en aquella ocasión era la de

dan cuenta de un posicionamiento reciente desde la escritura amazónica. Si los repertorios aparecen asociados a instituciones gubernamentales (Ministerio de Educación, Ministerio de Cultura), hay también, otras iniciativas que pueden incidir en el despojo cultural en que el investigador, suple, al sujeto de cultura, este sería el caso Nomatsiguengas (2016) de Marta Anducas. 
realidad y ficción, esta misma se constituye en la escritura de los relatos amazónicos: se trata de narrativas recopiladas que han sido dichas por los abuelos, su formato es de la palabra-voz, oral. Lo que se presenta es una reelaboración, una rescritura del mismo texto, cuyo límite está dado por la contingencia ética de lo que se escucha entre los pueblos y cómo la representa. Algo más: el sujeto de escritura es a la vez sujeto de la cultura, es decir, no se trata de una escisión entre el sujeto de la enunciación, el sujeto del enunciado y el referente, acaso sí en la producción toda vez que se trata del artefacto libro. Este tránsito, supone ciertos rasgos de autonomía y creatividad que dan lugar a una escritura que aquí reconoceremos como indígena y cuyos rasgos generales serían que captura toda la cosmovisión de una cultura, proporciona los mitos, da cuentas de los espíritus de la naturaleza (sean estos dadores, o ejecutores de maldades), al tiempo que inciden en tipos de relaciones que establecen los amazónicos, en su propia cultura, con las otras culturas y con los extraños y forasteros. Esta se consolida en tanto que la edición no sería un asunto técnico si no que hay correspondencia con lo que el sujeto de la cultura conoce, pero al mismo tiempo, con los narradores orales con los que trabaja: de "A'nämëi" la identificación de los narradores "Adolfo Ireyo de la CN San José de Karene, y Víctor Huenco, Pablo Tayori y Juan Mankehue de la CN Puerto Luz" (Patiachi 2015: 15). De esta suerte encontramos que no nos sorprende que estos textos aparezcan documentados, se precise la fuente, y al mismo tiempo estos relatos tienen ese lado de invención, de la creación que hace posible su trasmisión en los tiempos actuales.

La escritura como tal resulta un elemento ajeno, pero considerada importante para las transacciones con los otros, por lo que el resultado será una tensión entre las formas tradicionales de trasmisión de la cultura y de conservación de esta. En ese tránsito habría que preguntarnos cómo los indígenas imaginan el escenario para reproducir su propia experiencia cultural. Considero que el kené de la palabra sería la realización creativa de cualquier forma indígena que se registra. Es decir, la letra se comportaría como un diseño que permite trazar la palabra indígena: no se trata tanto si se respeta la tradición o si se oraliza la escritura, sino cómo esta escritura a su vez recrea formas de la tradición ancestral. Debe recordarse que el kené es el arte por excelencia, y que este es considerado escritura (RDINC 540). Esto alcanza un horizonte de lectura al insertarse, en todos los casos, dibujos y pinturas que acompañan al relato y quien lo expresa de manera singular es Pocon Quena.

\section{Contornos CUlturales (interpretativos)}

Planteo que nuestra aproximación interpretativa se haga de cara a la historia, pero al mismo tiempo a la especificidad de la cultura. El acercamiento a este tipo de texto no escapa de su propia escena sociocultural. Por lo que planteo que nuestra aproximación se realice tomando en cuenta algunas categorías centrales para la comprensión de las culturas amazónicas, me refiero a territorio y cosmovisión, al tiempo nos interesa la relación que establece la gente con la naturaleza y la especificidad de los espíritus, en el caso Shipibo- 
conibo. Ciertamente estas incisiones nos llevan a articular pares de diálogos que se desprenden de ellas: lengua-cultura ${ }_{s}$ gente-mundo, y, kené-memoria. Se trata, entonces, de un acercamiento que compromete pares dialógicos: primero, la cultura se manifiesta en la lengua, esta asume las características que cada comunidad, que cada pueblo le otorga. Cierto, la lengua representa la cultura, la cultura se manifiesta a través de la palabra, pero esta suele manifestar de distintas formas. La cultura expresa el ser social, por lo que la lengua obedece a la comprensión de dicha cultura.

El territorio es cultura. El espacio resulta clave en cualquiera de las culturas amazónicas. Es imposible imaginar un pueblo amazónico sin territorio. Este resulta de los diversos procesos históricos como migraciones o conflictos que los llevó a posesionarse de los espacios en lo que actualmente están localizados los pueblos indígenas. Es decir, desde allí se constituye también la humanidad amazónica. Está vinculado a la historia del pueblo amazónico: "los pueblos reclaman su territorio, el que han habitado, cuidado y controlado durante toda su historia, mucho antes de que el Perú existiese como Estado" (Chirif et al. 2002: 45). No debe perderse de vista que el territorio forma parte de su propia historia, que los indígenas amazónicos son los mejores guardianes del hábitat amazónico y como espacio limitado es pensado como "un territorio integral y no intercambiable por ningún otro". El territorio provee, no se puede estar en desventaja frente a otros; sería resultado de la extensión en que un pueblo se ha desplazado, aun cuando en el siglo XX, esto diera origen a las ciudades ribereńas. El concepto reporta como fundamento de existencia. Los actuales territorios a la vez se corresponden con los lugares en lo que se identifican las lenguas indígenas amazónicos (Minedu 2013). El pueblo Shipibo-conibo se asientan en los márgenes del río Ucayali (Ver Figura n ${ }^{\circ} 1$ ).

Como cultura los Shipibo-conibo asumen necesariamente una predefinición espacial, como un "asentamiento básicamente ribereño", por lo que resulta que "el territorio fluvial y/o lacustre y los álveos y barrizales son tanto o más fundamentales que la tierra firme" (Minsa 2003: 39). El territorio será el espacio de la convivencia entre un nosotros los humanos y las otras gentes, al tiempo que da lugar a otras dimensiones como la relación que establece con la naturaleza y los dioses y los espíritus.

Cada uno de los pueblos tiene su propia cosmovisión, en líneas generales se puede hablar de la relación que establece el hombre-dioses (incluido rituales, espíritus y mediadores) que reclama sus ancestros y a la vez todo aquello que posee como diferencia y como parte de lo que el común de estas culturas posee. Esto a su vez, invita a tomar en cuenta que cualquier proyecto narrativo viene impregnado por esa manera de ver-(sentir)entender el mundo, lo que equivale a decir, la manera cómo se expresan y comprenden los pueblos amazónicos su mundo y cómo esta palabra la manifiesta, lo que comúnmente llamamos cosmovisión. En el caso Shipibo-conibo, es "su" territorio donde la cosmovisión se concretiza como forma cotidiana o ritual. La mirada que se tiene sobre este mundo fue sintetizada por el Pakan Meni, Elí Sánchez, en El ojo verde: "Cuando se creó el mundo Shipibo, sólo estaba formado por el cielo y la tierra. Y estaban tan cerca, que las relaciones entre el hombre y los seres de la naturaleza eran muy fáciles" (Sánchez 2004). El mito 


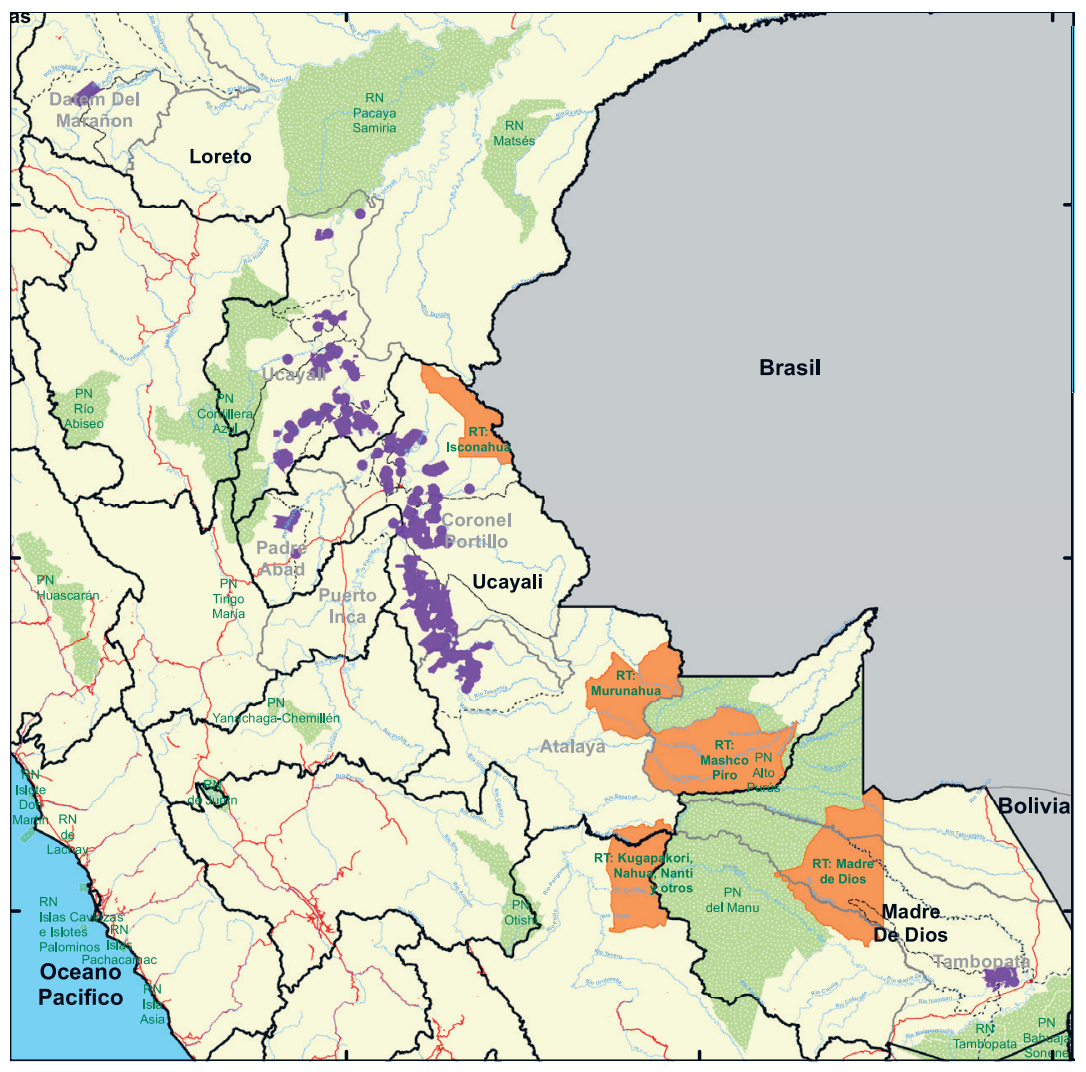

Figura $n^{\circ}$ 1: Mapa del pueblo Shipibo-Conibo Fuente: BDPI Base de Datos de Pueblos Indígenas u Originarios $<$ http://bdpi.cultura.gob.pe/node/26>

explica que los mellizos Kesten y Kesin "empezaron a lanzar flechas hacia el cielo y lograron formar una escalera" y cómo la gente "desobedecieron las reglas y [a] Bari Papa, el Padre Sol”. Luego de lo cual el cielo se fue alejando más y más, y el mundo se dividió "en cuatro espacios".

El primero, Jene Nete o mundo de las aguas, es donde habita el poderoso Ronin, la boa, quien tiene a su servicio a los jene chaikonibo, seres que viven en el agua. El segundo espacio es Non Nete o nuestro mundo, donde habitan los hombres y cuantos seres vivientes existen. También están los poderosos espíritus de las plantas y los animales, entre ellos el de la lupuna (yoshirapa) y el de la catahua, ambos muy temidos. 
El tercero es Panshin Nete o mundo amarillo, donde viven los espíritus malos. Allí van los curanderos o las personas que hacen daño o transgreden las reglas y son dirigidos por Simpira, un ser enorme con cuernos y brazos muy largos.

Por último, está Jakon Nete o espacio maravilloso donde está el Sol, acompañado de la Luna. Sólo las almas seleccionadas llegan a este mundo, aunque también pueden llegar las de los animales y las plantas. Las almas del Panshin Nete pueden llegar a este mundo con la ayuda del meraya, médico shipibo que ha alcanzado el grado superior (Landolt 2004) ${ }^{7}$.

Si el territorio es lugar de las realizaciones cotidianas y la percepción que se tiene del mundo, el non neten, nuestro mundo, allí donde el Shipibo-conibo habita, sabe desde las primeras gentes que no mora solo, que hay otros y que su relación con el universo es al mismo tiempo ritual y material, lo es con los seres que conviven con nosotros y al mismo tiempo con la naturaleza (una planta, un ave, un pez, tienen vida).

En el universo amazónico la relación entre la gente y otros humanos y el espacio respecto de sus relaciones entre humanidad y naturaleza de uno y la del resto, definen los contornos de la gente. En términos indígenas la relación entre la gente y la naturaleza es de equilibrio, por lo que se puede identificar una ética ecológica. Se consume lo necesario; se aprovecha el espacio y lo que este tiene para satisfacer las necesidades; no se puede abusar de esta, hacer lo contrario puede acarrear malestar, desorden y desequilibrio. Lo que equivale a destinar la vida al sufrimiento. Esta relación supone comprender que, desde las culturas amazónicas, la humanidad es compartida, el ser humano no está solo, sino que se realiza con otra distinta a la suya, de allí que el otro es al mismo tiempo gente, porque en el pasado, en el de los ancestros, la humanidad no se diferenciaba, un ser humano no se distinguía de un oso hormiguero; ni el paiche y el tucán, del humano. Estaban en el mismo espacio y se relacionaban como iguales.

Si bien podemos convenir que los dueños no es un tema exclusivo de los Shipibos y que corresponde a las diversas culturas, tanto amazónicas como andinas. Los registros de los dueños en las culturas amazónicas y andinas, vienen desde lejanos tiempos, en el caso de la Amazonía, podríamos recordar los relatos de Francisco Izquierdo Ríos ([1939] 2010), entre los dos más conocidos y de los que tenemos un buen acervo documental, corresponde al Chullachaqui y al Tunche . Del primero, este escritor amazónico señala que es "el diablo de pies desiguales y proteico, que se transforma, de un momento a otro" (Izquierdo Ríos 2010: 73), en cambio el segundo aparece como un demonio que hace travesuras y viene a llevarse el alma de la gente; se le escucha llorar o entrar a las viviendas: "-Donde s'oye llorar más al tunche es en los ríos, hom... Todas las noches s'eoye que llaman como que piden auxilio, después como que lloran..." (Izquierdo Ríos 2010: 82). Los dueños es un concepto

\footnotetext{
${ }^{7}$ Ver: <http://ojoverde.perucultural.org.pe/home.html>

${ }^{8}$ Puede revisarse los relatos "Chuchaqui” y "Tunchi” de Francisco Izquierdo Ríos en Ande y Selva [1939]. (Obras completas, t. I, 2010: 73-77; 79-83).
} 
extensivo a madre, que aparece en otras recopilaciones como la que Francisco Izquierdo Ríos realiza con José María Arguedas (1954, cf. Chirif, 2016: 105). La idea que está detrás de esto es el equilibrio entre los mundos y al mismo tiempo al interior de un mundo, el de aquí, por lo que la relación tiene que ser de armonía, entre gente-naturaleza. No se puede abusar de la naturaleza, el espacio es compartido con otras "gente" y esta gente es la que cuida la naturaleza. Por lo que, en términos generales, se trata de una forma de conferir a la naturaleza como entorno propio y compartido. Si todas las culturas amazónicas poseen los espíritus o dueños o madres de la naturaleza. La importancia que tienen los dueños en la cultura Shipibo-conibo, es clave para cualquier diálogo y posibilidad de comprensión.

En el mismo sentido, todas las culturas tienen estrategias particulares para expresarse. En este caso se trata de los kené, Shipibos con el dominio y manejo de los diseños. Se trata del legado ancestral que se actualiza contemporáneamente. El kené es la forma más lograda -y estética- de la cultura, se asocia al tejido, a la cerámica y al bordado, es al mismo tiempo, un ejercicio particular de las mujeres y se trasmite de madre a hija, como seńala Luisa Elvira Belaunde, en los "Shipibo-konibo, esta es expresada a través de su artesanía y el kené, es el sistema de diseńo característico de este pueblo", su estudio lo resume del siguiente modo:

Hacer kené, es decir pintar, bordar o tejer diseños, es un arte típicamente femenino, se enseña de madre a hija, que utiliza materiales variados, algunos derivados del bosque y las chacras, como los tintes naturales, las semillas y el algodón, y otros industriales, como las telas, los hilos de lana de colores y las cuentas de vidrio (Belaunde, 2012: 124).

En ese sentido, la palabra puede ser considera en boca de las mujeres un kené y expresado en la escritura y el dibujo, como la expresión que rapta la escritura y la vuelve en un nuevo espacio e instrumento para desarrollar el kené. Este aprendizaje, de acuerdo con la tradición oral viene de la hermana inca que muere por acción del sol, de ella aprenden el diseño. La otra, más bien se asocia los diseños que tienen la naturaleza, por ejemplo, los peces. Tales diseńos se aprecian en su cerámica, en sus textiles y ahora, se ha renovado en sus textos.

\section{KenÉ de la palabra: NarRativa Shipibo}

El kené es la forma de expresión de la cosmovisión Shipibo-conibo, un arte del diseńo, ejercida y trasmitida por las mujeres (Belaunde, 2009). El 16 de abril de 2008 fue declarado Patrimonio Cultural del Perú tal como indica la Resolución Directoral Nacional No 540-INC. ${ }^{9}$ Este documento advierte varias dimensiones que aquí recuperamos: a) "en lengua shipiba, designa al característico sistema de diseńo del pueblo shipibo-konibo"; b) "el diseño lineal o kené hace referencia [...] a la cosmología y los elementos vivos que la

${ }^{9}$ Ver: <http://administrativos.cultura.gob.pe/intranet/dpcn/anexos/41_1.pdf?1566927> 
conforman en los diversos niveles de la compleja cosmovisión amazónica"; c) "el kené es una manifestación polisémica"; y, d) "una escritura sobre el cosmos y sus componentes". La escritura alfabética la podemos imaginar como un diseño que pauta los elementos de la cultura, y al mismo tiempo se advierte, su polisemia. Esto en virtud de lo siguiente: se ha producido un tránsito de la forma tradicional de trasmisión de los saberes, de esta manera la palabra -la elegida siempre es la más expresiva y bella- y esto es lo que ocurre en el caso de Lastenia Canayo. Se trata del rapto de la escritura del invasor, que causa extrańeza y temor, por lo que se la arrebata para convertirla en instrumento propio para que obedezca al cómo y a la dinámica de la palabra-dibujo, que sería el diseño, narrar con la palabra, narrar con los colores.

Si la escritura resulta un proceso ajeno a la forma como se entiende los diseños gráficos, la instrumentalización de esta por el sujeto de enunciación indígena se contrapone con las formas tradicionales de trasmisión de la cultura. Entre los Shipibo-conibo la escritura es comprendida como diferente: "La escritura occidental es llamada joxo joni kené, "diseño de los blancos" y es un saber que se encuentra materializado sobre las hojas de los libros" (Belaunde, 2012: 131-132). El diseño del blanco no se entronca con el legado cultural de la gente del río Ucayali, me refiero al kené, que sería un don asociado a los espíritus, a los viajes que hacen las mujeres tanto como realizaciones del arte material "como [los] diseños vistos en visiones chamánicas y materializados sobre lienzos", extensible a los varones, los actuales pintores ${ }^{10}$. Desde esta perspectiva, entenderemos al kené de la palabra como aquella que apela a la memoria ancestral, utiliza el diseño, sus colores, fija la palabra hablada y la trasmite a otras generaciones.

El kené de la palabra tiene ya una trayectoria trazada. Lastenia Canayo publica Los dueños del mundo Shipibo (2004) como diálogo de saberes y la confluencia de la letra y el dibujo. Agrego el testimonio que trabaja Pilar Valenzuela Bismarck con Agustina Valera Rojas, Koshi shinanya ainbo, El testimonio de una mujer shipiba (2005), al que le sigue Xoké (2013) historieta que aparece como resultado de una experiencia trabajada con los shipiboconibos que llegaron a Lima, que se posicionaron de las orillas del río Rímac, en Cantagallo. Este trabajo consistió en hacer un recuento de los principales relatos de tradición ancestral y contemporánea, que fueron narrados por los abuelos y abuelas, que se fijó en una doble escritura (Shipibo-conibo y español) y la población participó en el dibujo de esta tira. Al mismo tiempo los gestores pensaron también en la circulación Xoké en soporte virtual y de libre acceso ${ }^{11}$. La historieta tiene el encanto de los dibujos, aparece como señales breves de lo que Elías Rengifo llama "libros de la comunidad", es decir, una suerte de coincidencia entre escritura y memoria oral, aun cuando su soporte sea contemporáneo. En ellos nos acercamos al universo Shipibo-conibo, a la tradición de las primeras gentes y al mito que han trasmitido, desde siempre, los abuelos.

\footnotetext{
${ }^{10}$ Nos referimos a las prácticas rituales de ayahuasca, que participar por igual, el sabio médico, la mujer Shipiba o los pintores.

${ }^{11}$ Ver: <https://www.youtube.com/watch?v=cJUaeCbjVWk>.
} 


\section{Carné de lastenia canayo}

Su nombre shipibo es Pacon Quena, "La que llama a los colores", proviene de la comunidad nativa Roroboya, en el Bajo Ucayali, donde nació en 1962. Su experiencia se asemeja a la de todos los Shipibos, movilidad social que enfrenta las carencias y que sobrevive a diversos escenarios sociales. De niña aprende a pintar diseños, a los ocho "bajo la protección de su abuelo, el viejo curaca Arístides García, fue pastora en la chacra de un colono”, estudió por entonces la primaria y pudo hacer la secundaria en Yarinacocha (cf. Canayo 2004: tapa). Desarrolla diversos trabajos, como toda mujer Shipibo, sostiene a su hogar con su trabajo de cerámica, telas y bordados. Cuando llega a Lima, ejerce diversos empleos. El historiador Pablo Macera lo invita a participar del Seminario de Historia Rural de San Marcos ${ }^{12}$, allí empieza una nueva forma de vida para ella, se ve allanada por la demanda de un trabajo que supone la divulgación de su cultura. Pablo Macera desarrolla el proyecto Cuentos pintados del Perú (1996-2002), que luego tendrá una especial atención con la Amazonía (1999-2004) en la que participan diversos narradores-pintores indígenas como Enrique Casanto Shingari, Lastenia Canayo, Herminio Vásquez, Robert Rengifo y Romer Yagkug Sejekam. Pacon Quena tiene esa curiosidad para el dibujo. Sabe, además narrar, no solo informar; sus trazos la definen como creadora, como tal, sujeto de la cultura Shipibo. Narra, pinta, teje y hace trabajos en madera. El universo que narra los puede llevar a plasmar en diversos soportes. Tiene el encanto del piripiri para la palabra, el trazo, el tejido y la madera. Ha escrito sobre los "dueńos" (ibos/yoshin).

El universo narrativo que ha trabajado Canayo es el de los "dueños del mundo", que en la década de 1940 se identificaba ya como "la madre de", es decir los espíritus que poseen la naturaleza, los animales e incluso las cosas. En la Amazonía, los dueños se asocian al concepto madres, para el primero Alberto Chirif en su Diccionario Amazónico, precisa: "Dueños. Cult. Seres protectores de animales y plantas a los cuales la gente tiene que pedir permiso para capturarlos. Son de género masculino o femenino.” (Chirif 2016: 126) y respecto a "Madres. Cult. f. Seres protectores de animales y plantas a los que considera sus hijos. La gente para cazar y aprovecharlos tiene que pedirles permiso a sus madres. En reciprocidad deben darles algo, por ejemplo, mapacho." (Chirif 2016::174). Entre los Shipibos se los identifica como Ibo-Yoshin, los dueños del mundo que, para Pablo Macera, "Son seres que premian, castigan, dan y quitan. Los Dueños son reconocidos como diferentes nombres por cada uno de los pueblos amazónicos” (Macera 2004: 5).

Los Ibo-Yoshin de Lastenia Canayo tiene una singularidad en lo que vengo proponiendo como escritura autónoma, de un lado, no viene en la lengua sino en la dimensión de la apropiación de la lengua franca, es decir en espańol, lo que sugiere diversos problemas de interferencia para el traslado legible de la cultura. Es la lengua que eligió. De otro lado, la doble dinámica que exige el texto: no se puede leer el relato sin mirar el

${ }^{12}$ Cf. Pinto Herrera, Honorio "Publicaciones del Seminario de Historia Rural Andina. 2001-2010" Nueva corónica 1 (Enero, 2013) ISSN 2306-1716 Página 1 <http://www.academia.edu/3269650/Seminario_de_ Historia_Rural_Andina_publicaciones_2001-2010>. 
dibujo como no se puede visualizar el dibujo sin leer la narración. En general sus escritos son breves, la eficacia de estos está en lo que informa y describe de manera llana en diálogo con el dibujo. En todos los casos sigue el siguiente patrón: una descripción del dueño, su relación con la gente y su utilidad, según sea el caso. Una dimensión adicional que debe agregarse es la capacidad creadora de Lastenia Canayo que ha llevado el kené de la pintura a la cerámica, de la tela pintada y el bordado a la escultura en madera y de esta, a un kené que es el de la palabra-pintura en su libro Los dueños del mundo Shipibo (2004).

\section{LOS DUENOOS DEL MUNDO SHIPIBO}

Publicado el 2004, Los dueños de mundo Shipibo presenta 104 kenés de la palabra, resultado de los "Ibo-Yoshin de la tradición oral shipiba recordados por Lastenia Canayo que durante los últimos siete años ha conseguido pintar y bordar más de trecientos Dueños con sus respectivas narraciones" (Macera 2004: 5). La singularidad del libro está en que no solo se lee un relato, sino que se ve una pintura del dueño; es decir, la escritura va acompañada por la pintura cuyo centro son los dueńos de las plantas (eventualmente, animales, cosas, etc.). La mayoría de los relatos son escritos por la propia narradora, eventualmente se ayuda de la transcripción de su colaboradora MBSC [María Belén Soria Casaverde]. Los escenarios de relato sin duda salen del espacio cotidiano. Serán suplantados por el kené de la palabra, que reinventa la memoria. No estamos reunidos en la maloca, ni en la madrugada ni la noche, ni el momento en que se traza los diseños o se teje, estamos ante la relación silenciosa entre el texto y un posible lector: el propio, Shipibo-conibo y aquellos que no son de dicha cultura. Esto es, los relatos no se dicen en su lugar tradicional, se consignan en otro espacio. No hay trasmisión directa sino indirecta, no está la abuela que cuenta a todos, ni tampoco la madre que narra para su hija, que la lleva sobre los saberes ancestrales. Y decimos kené en tanto diseño que supone una doble instancia: el relato y el dibujo. Sin duda esto nos sugiere una diversidad de problemas, si es la voz indígena o si es el otro, y cuáles son las transiciones que se observan en estos procesos de alteridad y las miradas y categorías de pensamiento (Zumthor 2010; Benveniste 1996).

Texto y dibujo, el relato, que se confronta con la tradición, que se captura con la letra, que evoca la tradición oral, que se teje con la palabra en el espacio en blanco. (Ver Figura ${ }^{\circ}$ 2). Si bien María C. Chavarría precisa que se trata de nuevas literacidades, en el sentido de ser sujetos y coyunturas socioculturales las que han emergido, y tal como ella muestra, se asocia a los movimientos sociales en los que "La escritura cobraba más sentido pues había una necesidad urgente de trasmitir sus mensajes a un colectivo mayor (Chavaría 2011: 10). Nuestra lectura, sugiere la creación de una nueva situación narrativa: el tránsito del recopilador indígena a narrador indígena y la realización del kené de la palabra con los matices de colores y trazos de los diseños e incorpora la planta y el dueño. Lo nuevo de este libro consiste en que no es posible el texto sin que se mire la pintura que lo acompańa, ambos aparecen como un todo constitutivo (la letra, junto, y al frente, la imagen). 


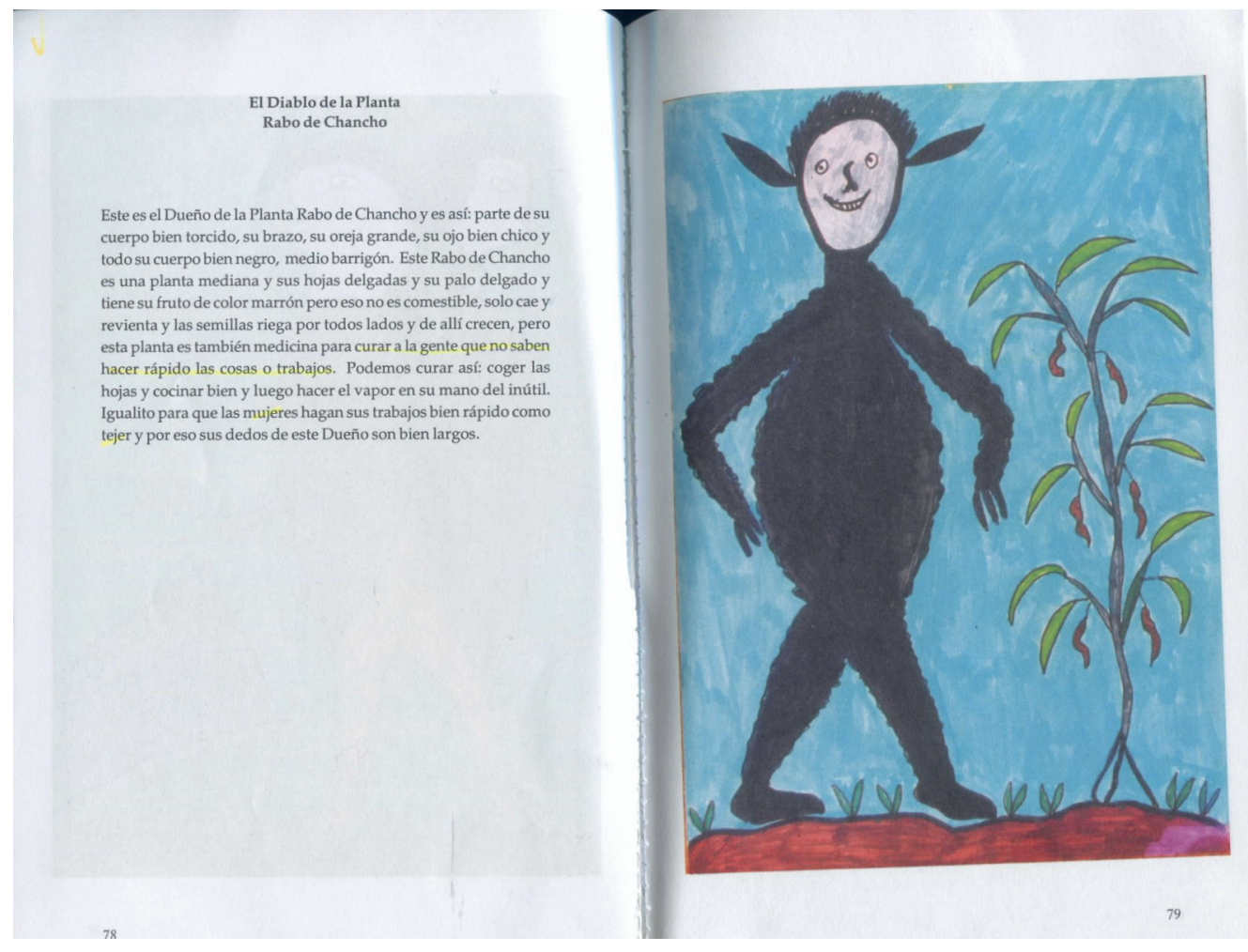

Figura $n^{\circ} 2$

Tomado Los dueños del mundo Shipibo de Lastenia Canayo (2004: 78-79)

Las pinturas de Lastenia Canayo, realizadas básicamente con plumones, aprehenden los contornos de la planta -eventualmente, objeto- de lo que se quiere comunicar. Así, en todas las imágenes encontramos un patrón que remite al saber que ella tiene como mujer sobre la flora. De esta suerte siempre aparece la planta en referencia y junto ella, el dueño. Las plantas son realizadas dentro de un naturalismo que da cuenta de las características de las plantas, detalles como las hojas, tallos o alturas, quedan refrendadas en los matices de colores. Los dueños aparecen vinculados a estas, son las características que tienen las plantas que el ibo yoshin perfila. La analogía creativa se produce a partir de las características de la planta, que Pacon Quena reelabora como plataforma cromática hiperrealista, por lo que la lectura nos llevan inevitablemente a ese doble estatus, en que dibujo y texto, según Macera, "se apoyan porque esta es una frontera entre oralidad y escritura" (Macera 2004: 8). Y en todos los casos pertenece a esa memoria que se narra más allá de que las consideremos "fantasías sin valor práctico (pero que) han servido durante siglos para constituir su código de conducta, la red de intercambios entre los shipibos y su entorno natural" (Macera 2004: 6-7). 
Los relatos de Los dueños del mundo Shipibo tienen una estructura narrativa que observa este patrón:

1. La descripción del dueño

2. La asociación del dueño con la planta (animal, cosa)

3. La utilidad de la planta

4. Localización, preparación y aplicación

5. Relación con el dueño (permiso)

6. Asociación con otros elementos

Esta línea narrativa evoca la sabiduría indígena, porque el principio que estaría aquí es la actualización de la cosmovisión, la trasmisión de la tradición y la cognición indígena. Entre los humanos hay situaciones que generan malestar, desorden y desequilibrio, para enfrentarlo, el poblador Shipibo-conibo tiene a su disposición un conjunto de narrativas que le indican los posibles "remedios" para esos males o necesidades. Entonces, ¿Qué enseña la tradición ancestral?, ¿qué y cómo son estos remedios?, ‘ a qué dueño hay que pedir permiso para los remedios si tenemos que afrontar emergencias (hemorragia, heridas, materiales), habilidades (puntería, hacer las cosas bien y rápido, etc.), conductas antisociales (robo, ocio, mezquindad), etc.? El dueño y el objeto de protección van a sufrir también las consecuencias de participar en "resolver" el problema, esto puede implicar pérdida, porque, siempre se pide permiso, se habla, se conversa con el dueño, a fin de que acepte, porque todo esto se hace con "cariño", ya que puede ocurrir que ya no crezca más la planta.

Cada relato empieza con un enunciado que describe al espíritu. Declara "Este es... es asî", luego del cual vendrá la descripción del espíritu:

Este es el Dueño de la Planta Rabo de Chancho y es así: parte de su cuerpo bien torcido, su brazo, su oreja grande, su ojo bien chico y todo su cuerpo bien negro, medio barrigón (Canayo 2004: 78).

La escritura es casi siempre hiperbólica, los muestra como excesivos y voluminosos, aunque adquiere características humanas. Tal descripción se correlaciona con la planta que protege. Luego de lo cual identifica su condición, que, por lo general, se asocia con la naturaleza (una planta, un ave, un pez, un insecto, etc.):

Este rabo de Chancho es una planta mediana y sus hojas delgadas y su palo delgado y tiene fruto de color marrón pero eso no es comestible, solo cae y revienta y las semillas riega por todos lados y de allí crecen, pero esta planta es también medicina para curar a la gente que no saben hacer rápido las cosas o trabajos. (2004: 78).

El dueño será antropomorfo y coincide con un rasgo hiperbólico: 
Esta es la Dueña de la Lengua de Perro y es así: su cabeza redonda, las muelas largas y su cuello alto y delgado, y su mano parece una hoja y tiene orejas grandes, por eso esta Dueña escucha de lejos y sabe lo que va hacer, y así es esta Dueña de Lengua de Perro Hembra (Canayo 2004: 166).

Eventualmente, esta se suspende para solo dar la descripción del dueño, en aras de la eficacia del relato:

La Diabla del Pájaro Picaflor es parecida a una señora pero de diferente forma, y es así: su cuerpo igual a los humanos, pero sus pies son delgados y con cuatro dedos, es barrigona y tiene cola, su pico es bien largo para chupar las flores, y sus ojos redondos. Esta diabla es una mujer muy hermosa, sus vestidos elegantes y olorosos (Canayo 2004: 170).

La misma que puede ir acompañada por información adicional de la planta, su relación con varones o mujeres, o descripciones que implican pautas para la preparación de la receta, el remedio que ayude, p.e., a conquistar un chico, "Hay dos clases de lengua de perro, una es de macho y otra de hembra" (Canayo 2004: 166); pero, el preparado no lo puede hacer cualquiera, hay un mínimo de cualidades que debe tener, la de ser sumamente cauteloso porque "Así dicen que esta planta es como pusanga, pero eso solo lo hace cuando sabes prepararla porque si no te puede volver loco" (Canayo 2004: 166). Por último, la narradora, se encarga de insistir en la utilidad del objeto, indica para qué sirve y qué poderes tiene la planta. De esta suerte resulta inevitable repetir que, por ejemplo, es un "gran remedio" o "gran medicina", con ello se expresa sus diversos usos, según sea la planta y su celador, tratamiento de enfermedades como hemorragia, heridas, "vómito y frío", ceguera; material para el kené y cerámicas; $y$, al mismo tiempo con el cuidado que tienen los Shipibos respecto a las cualidades identitarias, como ser laborioso, saber controlar el hambre o ser moderado, estas serán "cualidades positivas" o cualidades negativas, controlar a las "personas abusivas" o "no ser tragón". De esta manera en el relato se instala cuando menos dos condiciones de verosimilitud o autoridad, la propia voz narrativa declara: "Así es este Dueño" (Canayo 2004: 10), que resulta la palabra de una voz que tiene el dominio y saber, es decir, su posición es la de un testigo que conoce. "Este es el Dueño" se convalida con "Así es este Dueño" (Canayo 2004: 10, 20), con “y así es" (Canayo 2004: 70) o con "Este...". (Canayo 2004: 78). La misma que se respalda en la palabra de los ancestros, ya que apela a la condición de pertenencia: "costumbre de los antepasados y en el tiempo viejo"; que da identidad y la actualiza en el nuevo contexto: un nuevo espacio, ya no es el bosque, ni el río, ahora transita por la urbe y, desde ella, se trasmite la cultura en un nuevo soporte.

Esta palabra describe, precisa y comporta una doble estrategia: el lector "asume" el relato y a la vez, los deícticos terminan por remitirlo al dibujo. De esta manera la autonomía del diseño resulta autosuficiente en sí misma, ibo-yoshin y planta quedan imaginadas en la masa cromática de la página. Hay en esto un doble estatus: palabra y pintura, resulta al 
mismo tiempo cuerpo de un mismo asunto. No se miran por separados. El dibujo siendo suficiente en sí mismo, se precisa, cuando el lector se acerca al proyecto. La narración se asume como parte de la comunidad, como expresión transcribe la palabra colectiva. Establece un equilibrio inestable (el de los formalistas) que se percibe en el objeto libro. La de Panon Quena simplemente corresponde a una shipiba que tiene posibilidad de crear un kené, escribir y dibujar, y con ello trasmitir, en un nuevo contexto su propia cultura. Doble apelación a la propia descripción y al dibujo/ tejido que alude el relato: el kené de la palabra.

\section{Conclusiones}

Los dueños del mundo Shipibo, consagra el kené de la palabra. Lo convierte en un libro singular, en el que la palabra sopesa su autonomía con el trazo cromático y ambos a la vez se complementan. Alcanza como saga del arte femenino, aun cuando el soporte sea otro, la vigencia de la tradición de los ancestros, la trasmisión de la sabiduría en nuevos contextos y trasgrede la "letra del blanco"; y, al mismo tiempo, sugiere una reinterpretación del territorio como espacio doble que evoca la transparencia de las aguas del río o la bruma del bosque. Su producción, con el añadido de que en el caso de la cultura Shipibo-conibo se caracteriza por su tradición migratoria, lo que hace que los espacios tradicionales varíen, entonces, ¿cómo preservar las formas tradicionales del ser cultural Shipibo-conibo? Es decir, cómo se afirma, recrea o reinventa la misma. En ese contexto es posible señalar la función del relato que se posesiona como formulación cosmopolita en tanto cuenta la sabiduría de una colectividad, al mismo tiempo, al hacerlo, se trasmite el inventario de los ibo-yoshin. Los espíritus participan del orden social y natural, en la armonía del universo compartido. Así, Lastenia Canayo, describe teniendo en cuenta las características de las plantas, en su lengua, y esta palabra, termina de dar forma aquello que resultaba un género y abstracción, y simultáneamente, cosmovisión, que alcanza corporalidad, que deja de ser solo un cuerpo: el Ibo-Yoshin y como ha escrito Chavarría son testamentos de la sabiduría. Es decir, la cartografía de la fauna amazónica sea como plantas medicinales, a las que siempre hay que andar con cuidado, saber pedir permiso a su dueño y tener mucho cuidado con lo que se hace "solo lo hace cuando sabes prepararla porque si no te puede volver loco" (Canayo 2004: 166). Ciertamente asistimos a un programa progresivo en que los recopiladores indígenas pasan a formar parte de un nuevo escenario letrado, la condición de creadores, y con ello, la aparición del escritor indígena amazónico que escribe desde su cultura. Se corresponde con el tiempo en que los indígenas han raptado la escritura; tienen el dominio de la letra, en su cultura y la cultura dominante. En el caso de Los dueños del mundo Shipibo resulta uno de los proyectos escriturales más importante producido durante estos primeros ańos del siglo XXI porque se entrega por primera vez un trazo, una imagen, de cómo serían estos espíritus. Y dos, porque plantea, un nuevo problema a la escritura. Esta imagen difusa ahora es posible visualizarla en primera persona, la de una Shipibo-conibo como Lastenia Canayo, mejor dicho, de Pecon Quena, que desde su condición de mujer ha llevado el diseño y la palabra a convertirla en el kené de la palabra. 


\section{OBRAS CITADAS}

Abregú Esteban, Karen Juliett. 2013. El libro sagrado de los Cashinahuas. Iquitos: Editorial Grupo Literario Ikitos.

AIDESEP-Iquitos. 1992. Cácámeewa y otros relatos indígenas y ribereños. Lima: AIDESEPOficina Regional Iquitos - Programa de Formación de Maestros Bilingües de la Amazonía Peruana FORMABIAP.

AMABISEC. 2009. Opempe. Oshintsinka noñane. El poder de mi lengua. Relatos orales ashaninkas y nomatsiguengas. Lima: Andesbook.

Almanocid Leya, Leo Laman. 2015. Relatos orales ashaninka. Recopilación, investigación y traducción de Leo Almanocid Leya. Lima: MINEDU - Digeibira.

Belaunde, Luisa Elvira. 2012. "Diseños materiales e inmateriales: la patrimonialización del kené shipibo-konibo y de la ayahuasca en el Perú”. Mundo Amazónico 3: 123-146. . 2009. Kené. Arte, ciencia y tradición en diseño. Lima: Instituto Nacional de Cultura.

Benveniste, Emile. 1995. "Categoría de pensamiento y categorías de lengua”. En: Problemas de Lingüistica General. t. I. México: Siglo XXI. 63-74.

Canayo, Lastenia. 2004. Los dueños del mundo Shipibo. Presentación y coordinador de la edición Pablo Macera. Lima: Universidad Nacional Mayor de San Marcos.

Casancho Leguía, Domingo [Mabanga Kasantyo]. 2010. Irogotane nomatsigenga. Secretos nomatsigengas de la Selva Central. Lima: Pakarina ediciones.

Chavarría Mendoza, María C. 2015. Eseha Echiikiana Esoiho. Con la voz de nuestros viejos antiguos. Tradición oral ese eja. Recopilación, investigación y traducción María C. Chavarría. Relatores Tadeo Mishaja Tii Hewa, Roberto Masías Sehue, Mateo Viaeja y Pedro Mishaja Shajaó. Lima: Ministerio de Cultura.

Chavarría, María C. 2011. "De la oralidad a la literacidad: aproximaciones recientes en la Amazonía”. En: Jean Pierre Chaumeil, Óscar Espinosa de Rivero \& Manuel Cornejo Chaparro. Eds. Por donde hay soplo: estudios amazónicos en los países andinos. Lima: IFEA, CAAAP, EREA LESC. [Recuperado de: <http://www.academia.edu/5913465/ De_la_oralidad_a_la_literacidad $>$ ].

Chihuailaf, Elicura. 1999. Recado confidencial a los chilenos. Santiago de Chile: Ed. LOM.

Chirif Tirado, Alberto; Pedro García Hierro \& Alexandre Surrallés. 2002. Historia para el futuro. Territorios y Pueblos Indígenas en Alto Amazonas. Yurimaguas, Perú: CORPI Coordinadora Regional de los Pueblo Indígenas de San Lorenzo. [Recuperado de: <http://www.iwgia.org/iwgia_files_publications_files/0345_Una_Historia_para_ el_Futuro.pdf $>$ ].

Chirif, Alberto. 2016. Diccionario Amazónico. Voces del castellano en la selva peruana. Lima: Lluvia editores, CAAAP.

Chirif, Alberto \& Manuel Cornejo Chaparro. Eds. 2009. Imaginario e imágenes de la época del caucho: los sucesos del Putumayo. Lima: CAAAP/IWGIA/UPC.

CILA. 2012. Shipibo, territorio, historia y cosmovisión. Investigación Aplicada a la Educación 
Intercultural Bilingüe. Proyecto dirigido por María Cortez. Lima: CILA-Universidad Nacional Mayor de San Marcos, UNICEF.

CVR. 2003. . Informe Final - Comisión de la Verdad y Reconciliación. Lima: CVR Comisión de la Verdad y Reconciliación. Tomo V. 241-277. [Recuperado de: http://bit. ly/1650FYx].

COMUNIDAD NATIVA YANESHA. 2012. Mitos y leyendas de la nación Yanesha. Oxapampa, Perú: Comunidad Nativa de Tsachope, Chontabamba - Ed. Dadaktis.

DEFENSORÍA DEL PUEBLO. 2016, noviembre, 7. Cronología: el caso de la comunidad indígena urbana Shipibo-Konibo de Cantagallo. [Blog]. [Recuperado de: <http:// www.defensoria.gob.pe/blog/cronologia-caso-comunidad-indigena-urbana-shipibokonibo-de-cantagallo/>].

Dussel, Enrique. 1994. El encubrimiento del Otro. Hacia el origen del "mito de la Modernidad". La Paz: Plural editores.

FUCSHICO. 1998. Non requenbaon shinan, El origen de la cultura Shipibo-Conibo. Leyendas-Historias-Costumbres-Cuentos. Ed. bilingüe Shipibo-Conibo-Castellano. Lima: FUCSHICO Fundación Cultural Shipibo-Conibo, Arteidea editores.

Hall, Stuart. 2010. Sin garantías. Trayectorias y problemáticas de los estudios culturales. Ed. de Eduardo Restrepo, Catherine Walsh y Víctor Vich. Lima: IEP, Universidad Andina Simón Bolívar, Pontificia Universidad Javeriana, Envión Ediciones.

Izquierdo Ríos, Francisco. 2010. Obra Completa, tomo I. Ande y selva. Ed. de Gladys Flores Heredia. Lima: Fondo editorial UNSMM-Gobierno Regional de San Martín.

Landolt, Gredna \& Carlos Dávila Herrera. 2004. El ojo verde. Cosmovisiones amazónicas. Lima: Fundación Telefónica, Programa de Formación de Maestros Bilingües de la Amazonía Peruana FORMABIAP. [Recuperado de: <http://ojoverde.perucultural. org.pe/home.html>].

Macera, Pablo. 2004. "Presentación”. Los dueños del mundo Shipibo de Lastenia Canayo. Lima: Universidad Nacional Mayor de San Marcos. 5-9.

Mariátegui, José Carlos. [1928] 1987. 7 ensayos de interpretación de la realidad peruana. 49a ed. Lima: Biblioteca Amauta.

Mayor Aparicio, Pedro \& Richard E. Bobmer. 2009. Pueblos Indígenas Amazonia Peruana. Iquitos: Centro de Estudios Teológicos de la Amazonía CETA. [Recuperado de: $<$ http://atlasanatomiaamazonia.uab.cat/pdfs/PueblosIndigenasAmazoniaPeruana. $\mathrm{pdf}>$ ].

MINEDU. 2013. Documento Nacional de Lenguas originaria del Perú. Lima: Ministerio de Educación del Perú.

MINSA. 2003. Análisis de la situación de salud del pueblo Shipibo-Konibo. Lima: Ministerio de Salud del Perú, Oficina General de Epidemiología.

Patiachi Tayori, Yesica. 2015. Relatos orales harakbut. Recopilación, investigación y traducción de Yesisca Patiachi. Dibujos de Huber Tayori Takori y Ronald Achahui Daridari. Lima: Minedu - Digeibira.

Ribeiro, Darcy \& Mary Ruth Wise. 1978. Los grupos étnicos de la Amazonía Peruana. Co- 
munidades y Culturas Peruanas, 13. Lima: Ministerio de Educación - Instituto Lingüístico de Verano. [Recuperado de: <http://library.osu.edu/projects/popolwuj/folios_esp/PWfolio_Escolios6_r_es.php>].

San Román, Jesús Víctor. 1994. Perfiles históricos de la Amazonia Peruana. 2a ed. Iquitos: Centro de Estudios Teológicos de la Amazonia, Centro Amazónico de Antropología y Aplicación Práctica, Instituto de Investigaciones de la Amazonía Peruana. [Recuperado de: <http://www.iiap.org.pe/Upload/Publicacion/L009.pdf>].

Tello Imaina, Leonardo. Ed. 2016. Karuara. La gente del río. Ed. Bilingüe Kukama-Castellano. Ilustraciones de niños y niñas kukuma del abajo río Marañón. Editores literarios Leonardo Tello Imaina y Stephanie Boyd. Dibujos. Lima: Wainakana Kamatawara Kana Organización Kukama Kukamiria de mujeres trabajadoras Comunidad Nativa de Parinari, Loreto, Perú), Radio Ucamara Instituto de Promoción Social Amazónica), Asociación Quisca.

Valenzuela Bismarck, Pilar \& Agustina Valera Rojas. 2005. Koshi shinanya ainbo, El testimonio de una mujer shipiba. Lima: Fondo Ed. Facultad de Ciencias Sociales UNMSM. Zumthor, Paul. 2010. Introdução à poesia oral. Belo Horizonte: UFMG. 
